\begin{tabular}{|l|l|l||}
\hline \multicolumn{2}{|c|}{ PublisherInfo } \\
\hline \hline PublisherName & $:$ & BioMed Central \\
\hline \hline PublisherLocation & $:$ & London \\
\hline \hline PublisherImprintName & $:$ & BioMed Central \\
\hline \hline
\end{tabular}

\title{
European Virtual Institute for Genome Annotation receives $€ 12$ million
}

\begin{tabular}{|l|l|l||}
\hline \multicolumn{2}{|c|}{ ArticleInfo } \\
\hline \hline ArticleID & $:$ & 4907 \\
\hline \hline ArticleDOI & $:$ & $10.1186 /$ gb-spotlight-20040127-01 \\
\hline \hline ArticleCitationID & $:$ & spotlight-20040127-01 \\
\hline \hline ArticleSequenceNumber & $:$ & 259 \\
\hline \hline ArticleCategory & $:$ & Research news \\
\hline \hline ArticleFirstPage & $:$ & 1 \\
\hline \hline ArticleLastPage & $:$ & 2 \\
\hline \hline & & RegistrationDate : 2004-1-27 \\
ArticleHistory & $:$ & OnlineDate \\
\hline \hline ArticleCopyright & $:$ & BioMed Central Ltd2004-27 \\
\hline \hline ArticleGrants & $:$ & \\
\hline \hline
\end{tabular}




\begin{tabular}{|l|l|l|}
\hline ArticleContext & $:$ & 130594411 \\
\hline
\end{tabular}

\section{Genome Biology}

Email: editorial@genomebiology.com

Janet Thornton, Director of the European Bioinformatics Institute(EBI; Hinxton, UK), is coordinator of the BioSapiens project. "The BioSapiens Network of Excellence ... will coordinate and focus excellent research in bioinformatics, by creating a Virtual Institute for Genome Annotation. The Institute will also establish a permanent European School of Bioinformatics, to train bioinformaticians and to encourage best practice in the exploitation of genome annotation data for biologists," she adds.

The annotations will be integrated and made freely accessible via a web portal, and will be used to guide future experiments. Annotations will be integrated using the Open Source Distributed Annotation System(DAS) developed by Lincoln Stein and colleagues at Cold Spring Harbor Laboratory (USA) for exchanging genome annotations.

"The development of methods, tools, and servers in close interaction with experimentalists is one feature that distinguishes the network from previous pan-European efforts in bioinformatics," says Thornton, "and although there are 24 formal partners, BioSapiens is not a closed shop: once the infrastructure is established, a primary goal is to make this an open network to promote bioinformatics throughout Europe."

BioSapiens is coordinated by a steering committee comprising Thornton (chair), Søren Brunak (Technical University of Denmark), Anna Tramontano (University of Rome "La Sapienza", Italy) and Alfonso Valencia (Consejo Superior de Investigaciones Científicas, Madrid, Spain), and a project manager, Kerstin Nyberg (EBI).

\section{References}

1. The Council of the European Union, [http://www.ebi.ac.uk]

2. Distributed Annotation System, [http://biodas.org/] 